\title{
Bonding and Singlet-Triplet Gap of Silicon Trimer: Effects of Protonation and Attachment of Alkali Metal Cations
}

\author{
Nguyen Minh Tam, ${ }^{[a, b]}$ Tran Dieu Hang, ${ }^{[b]}$ Hung Tan Pham, ${ }^{[a]}$ Huyen Thi Nguyen, ${ }^{[b]}$ \\ My Phuong Pham-Ho, ${ }^{[a]}$ Pablo A. Denis, ${ }^{[c]}$ and Minh Tho Nguyen ${ }^{[b]}$
}

We revisit the singlet-triplet energy gap $\left(\Delta E_{\mathrm{ST}}\right)$ of silicon trimer and evaluate the gaps of its derivatives by attachment of a cation $\left(\mathrm{H}^{+}, \mathrm{Li}^{+}, \mathrm{Na}^{+}\right.$, and $\left.\mathrm{K}^{+}\right)$using the wavefunction-based methods including the composite $\mathrm{G} 4$, coupled-cluster theory $\operatorname{CCSD}(\mathrm{T}) / \mathrm{CBS}$, CCSDT and CCSDTQ, and CASSCF/CASPT2 (for $\mathrm{Si}_{3}$ ) computations. Both ${ }^{1} \mathrm{~A}_{1}$ and ${ }^{3} \mathrm{~A}_{2}^{\prime}$ states of $\mathrm{Si}_{3}$ are determined to be degenerate. An intersystem crossing between both states appears to be possible at a point having an apex bond angle of around $\alpha=68 \pm 2^{\circ}$ which is $16 \pm 4 \mathrm{~kJ} / \mathrm{mol}$ above the ground state. The proton, $\mathrm{Li}^{+}$and $\mathrm{Na}^{+}$cations tend to favor the low-spin state, whereas the $\mathrm{K}^{+}$cation favors the high-spin state. However, they do not modify significantly the
$\Delta E_{\mathrm{ST}}$. The proton affinity of silicon trimer is determined as $\mathrm{PA}\left(\mathrm{Si}_{3}\right)=830 \pm 4 \mathrm{~kJ} / \mathrm{mol}$ at $298 \mathrm{~K}$. The metal cation affinities are also predicted to be $\mathrm{LiCA}\left(\mathrm{Si}_{3}\right)=108 \pm 8 \mathrm{~kJ} / \mathrm{mol}$, $\mathrm{NaCA}\left(\mathrm{Si}_{3}\right)=79 \pm 8 \mathrm{~kJ} / \mathrm{mol}$ and $\mathrm{KCA}\left(\mathrm{Si}_{3}\right)=44 \pm 8 \mathrm{~kJ} / \mathrm{mol}$. The chemical bonding is probed using the electron localization function, and ring current analyses show that the singlet three-membered ring $\mathrm{Si}_{3}$ is, at most, nonaromatic. Attachment of the proton and $\mathrm{Li}^{+}$cation renders it anti-aromatic. (c) 2015 Wiley Periodicals, Inc.

DOI: $10.1002 / j c c .23856$

\section{Introduction}

Continuing interest in small silicon clusters is mainly driven by the intensive searches for building blocks to be used as assemblies forming new types of optoelectronic nanomaterials and semiconductor devices. ${ }^{[1-4]}$ The simplest silicon cluster $\mathrm{Si}_{3}$ is also of astrophysical interest as it was detected in the absorption and emission spectra of carbon stars and comets. ${ }^{[5,6]}$ This triatomic species was produced in the 1980s in a number of mass spectrometry experiments using, among others, photofragmentation technique, ${ }^{[7]}$ and laser vaporization followed by a free jet expansion technique. ${ }^{[8]}$ Its electronic structure and spectroscopic parameters were subsequently the subject of several experimental, ${ }^{[4,9-15]}$ and theoretical studies. ${ }^{[16-26]}$ Thermochemical parameters including the total atomization energy (TAE), heat of formation, ionization energy, and electron affinity of $\mathrm{Si}_{3}$ were also determined. ${ }^{[20,26-28]}$

The carbon $\left(\mathrm{C}_{3}\right)$ and silicon $\left(\mathrm{Si}_{3}\right)$ trimers form a set of representative examples illustrating a sharp difference between the elements across the Periodic Table. While $C_{3}$ has a singlet linear structure $\left(X^{1} \Sigma_{\mathrm{g}}^{+}\right)$which is located at $1.91 \mathrm{eV}\left(16930 \mathrm{~cm}^{-1}\right)$ below the triplet linear $\mathrm{a}^{3} \Pi_{\mathrm{u}}$ state, ${ }^{[29]} \mathrm{Si}_{3}$ is strongly bent with two close-lying low-spin ${ }^{1} \mathrm{~A}_{1}\left(C_{2 \mathrm{v}}\right)$ and high-spin ${ }^{3} \mathrm{~A}_{2}^{\prime}\left(D_{3 \mathrm{~h}}\right)$ states. Previous extensive quantum chemical computations pointed out that the singlet $C_{2 v}$ structure is the lowest-lying state of $\mathrm{Si}_{3}$, but the corresponding singlet-triplet gap turns out to be small, calculated in the range of $4-15 \mathrm{~kJ} / \mathrm{mol}$ depending on the methods used. ${ }^{[24,26]}$

Spectroscopic characterizations of $\mathrm{Si}_{3}$ were also ${ }^{[1]}$ complex and not straightforward. Most of reported spectroscopic information arose from infrared spectra recorded under different conditions. Let us mention a few important results. Arnold and Neumark $^{[9 \mathrm{~b}]}$ used threshold photodetachment zero electron kinetic energy (ZEKE) spectroscopy of the $\mathrm{Si}_{3}^{-}$anion and observed vibrational separations of 501 (symmetric stretching $\mathrm{a}_{1}$ ) and $337 \mathrm{~cm}^{-1}$ (degenerate $\mathrm{e}^{\prime}$ ) which they attributed to transitions from the $\mathrm{Si}_{3}^{-}$anion to the low-lying ${ }^{3} \mathrm{~A}_{2}^{\prime}$ state of $\mathrm{Si}_{3}$. Although the $\mathrm{X}$-band probed in the ZEKE spectrum indicated the presence of a neutral species, this does not correspond to a singlet $C_{2 v} S_{3}$. These authors concluded that the transitions from the anion to the ${ }^{1} A_{1}$ state of $S_{3}$ in the ZEKE experiment were too weak to be observed. ${ }^{[9 b]}$

On the contrary, McCarthy and Thaddeus ${ }^{[12]}$ were able to record the rotational spectrum of $\mathrm{Si}_{3}$ and their analysis led to a conclusion that the recorded spectrum mainly arose from a singlet state whose shape was determined to be an isosceles triangle $\left(C_{2 v}\right.$ point group with a $\mathrm{Si}-\mathrm{Si}$ bond to the apex $\mathrm{Si}$ of length $2.177 \AA$ and an apex angle $\alpha=78.1^{\circ}$ ). More recently, Reilly et al. ${ }^{[13]}$ produced $\mathrm{Si}_{3}$ in a pulsed discharge of silane in $\mathrm{Ar}$, and recorded its excitation spectrum in the region of

[a] N. M. Tam, H. T. Pham, M. P. Pham-Ho Institute for Computational Science and Technology (ICST), Quang Trung Software City, Ho Chi Minh City, Vietnam

[b] N. M. Tam, T. D. Hang, H. T. Nguyen, M. T. Nguyen Department of Chemistry, University of Leuven, B-3001 Leuven, Belgium E-mail: minh.nguyen@chem.kuleuven.be

[c] P. A. Denis Computational Nanotechnology, DETEMA Facultad de Quımica, Gral, UDELAR, Flores 2124, CC 1157, 11800, Montevideo, Uruguay Contract grant sponsor: ICST (Department of Science and Technology of Ho Chi Minh City, Vietnam)

(c) 2015 Wiley Periodicals, Inc. 
$18,000-20,800 \mathrm{~cm}^{-1}$. These authors found that the observed spectrum is dominated by a triplet-triplet transition of the $D_{3 \mathrm{~h}}$ trimer and were not able to detect a singlet $C_{2 \mathrm{v}}$ isomer in fluorescence conditions. ${ }^{[13]}$ We recently carried out high accuracy quantum chemical computations using coupledcluster theory at the complete basis set level (CCSD(T)/CBS) to determine the heat of formation of $\mathrm{Si}_{3}$ and found that both ${ }^{1} A_{1}$ and ${ }^{3} A_{2}^{\prime}$ states are indeed very close in energy, with a S-T energy separation of $2-10 \mathrm{~kJ} / \mathrm{mol}$ in favor of the low-spin state. ${ }^{[26]}$

Available experimental and theoretical results thus suggest that silicon trimer can exist in both singlet and triplet manifolds and can independently be produced. It is well known that the singlet-triplet gap of a molecule is a fundamental energetic parameter, in particular in the cases where such a gap is small. In the case of $\mathrm{Si}_{3}$, each state could eventually lead to a distinct growth pattern of silicon clusters. Therefore, much effort has been devoted to accurately determine this quantity. Formation of larger $\mathrm{Si}_{n}$ clusters in either the closedshell or a high-spin state, could equally be of interest, depending on the subsequent applications. For example, stable triplet clusters could be considered as potential starting blocks for magnetic materials. In this context, a legitimate question concerns the possible singlet-triplet intersystem crossing as both low-energy states of $\mathrm{Si}_{3}$ are geometrically separated from each other by only a small closure, or opening, of the apex bond angle $\alpha$ (being 78 and $60^{\circ}$ in the singlet and triplet states, respectively, as mentioned above).

It is also well known that electronic and molecular properties of elemental clusters can basically be modified following doping. ${ }^{[4,30]}$ A point of interest here is to what extent the singlet-triplet degeneracy of $\mathrm{Si}_{3}$ can be changed by a simple attachment of a proton or an alkali metal cation. A cation, with appropriate properties, could serve as a linker for further assemblage of clusters. In a previous study, ${ }^{[31]}$ we found that lithium cations play the role as linkers connecting units of $\mathrm{Ge}_{9}$ clusters to generate $\mathrm{Ge}_{n} \mathrm{Li}_{m}$ nanowires. We are thus concerned with a basic question if a $\mathrm{M}^{+}$cation could substantially stabilize either the singlet or the triplet of silicon trimer. This issue is related to a possibility to assembly structures such as $\left[\mathrm{Si}_{3^{-}}\right.$ $\left.\mathrm{M}^{+}-\mathrm{Si}_{3}-\mathrm{M}^{+}\right]_{n}$ in which $\mathrm{Si}_{3}$ are potential building blocks and $\mathrm{M}^{+}$ the linkers, and the resulting materials could bear either a lowor high-spin state.

In relation to our recent studies on doped silicon clusters, ${ }^{[4,25,26,30]}$ we set out to address the questions mentioned above in determining in particular the singlet-triplet energy separations following attachment of a cation to $\mathrm{Si}_{3}$. These include the proton which is the simplest cation, and the alkali metal cations $\mathrm{Li}^{+}, \mathrm{Na}^{+}$, and $\mathrm{K}^{+}$. The positive charge is needed to keep an even number of electrons and thereby both singlet and triplet electronic states of the resulting products. Using high accuracy quantum chemical methods, we thus determine the most stable geometry of each cluster in two electronic states, and thereby evaluate singlet-triplet energy separations $\left(\Delta E_{\mathrm{ST}}\right)$. The electronic distribution and chemical bonding of the cationic clusters are subsequently analyzed to understand the effects of cation attachment.

\section{Computational Methods}

All electronic structure calculations are carried out using the Gaussian 09, ${ }^{[32]}$ Molpro 2008 ${ }^{[33]}$ CFOUR $^{[34] *}$ and MRCC $^{[35,36]}$ suites of programs. In our recent studies, we demonstrated that a consistent set of thermochemical parameters of silicon clusters can be determined using the composite G4 method, and the G4 results are close to those obtained using the coupled-cluster theory at the complete basis set $\operatorname{CCSD}(T) /$ $\mathrm{CBS}^{[26]}$ In this work, both $\mathrm{G} 4$ and $\mathrm{CCSD}(\mathrm{T}) / \mathrm{CBS}$, where possible, methods are used to obtain energetic values. In the composite G4 procedure, ${ }^{[37]}$ geometry optimizations and vibrational calculations are performed using the popular hybrid B3LYP functional in conjunction with the $6-31+\mathrm{G}(2 \mathrm{df}, \mathrm{p})$ basis set. ${ }^{[37]}$ In the $\operatorname{CCSD}(\mathrm{T}) / \mathrm{CBS}$ protocol, single-point electronic energies are calculated using the restricted/unrestricted coupled-cluster R/UCCSD(T) formalism with the correlation consistent aug-cc-pVnZ (aVnZ, $n=\mathrm{Q}$ and 5) basis sets, ${ }^{[38]}$ based on $\operatorname{CCSD}(\mathrm{T}) /$ aug-cc-pVQZ optimized geometries. The $\operatorname{CCSD}(T)$ energies are then extrapolated to the CBS limit energies using expression $(1)^{[39]}$ :

$$
E(x)=E_{\mathrm{CBS}}+B / x^{3}
$$

where $x=4$ and 5 for the $\mathrm{aVnZ}$ basis, $n=\mathrm{Q}$ and 5, respectively, and also $x=5$ and 6 for $n=5$ and 6 . In this protocol, zero-point energies (ZPE) are calculated from (U)CCSD(T)/augcc-pVQZ harmonic vibrational frequencies.

Other quantum chemical methods including the density functional theory (DFT), CASSCF/CASPT2, CCSDT, and CCSDTQ are also used to determine the S-T gaps, and these methods will be described in a following section. For an analysis of electronic distribution, we make use of the electron localization function (ELF) ${ }^{[40]}$ and ring current ${ }^{[41]}$ approaches. The magnetic responses are computed using the Gamess-UK program. ${ }^{[42]}$ Calculations of the ring current are carried out using the CTOCD-DZ method $^{[43]}$ implemented in the SYSMO program, ${ }^{+}$ which is connected to Gamess-UK

\section{Results and Discussion}

\section{A qualitative analysis of the electronic states: The Walsh diagrams of $\mathrm{Si}_{3}$}

Geometries and vibrational parameters of silicon trimer were well determined and abundantly discussed in the literature quoted above. The main geometrical characteristic of $\mathrm{Si}_{3}$ is

*Basis sets were obtained from the Extensible Computational Chemistry Environment Basis Set Database, Version 7/30/02, as developed and distributed by the Molecular Science Computing Facility, Environmental and Molecular Sciences Laboratory which is part of the Pacific Northwest Laboratory, P.O. Box 999, Richland, Washington 99352, USA, and funded by the U.S. Department of Energy. The Pacific Northwest Laboratory is a multi-program laboratory operated by Battelle Memorial Institue for the U.S. Department of Energy under contract DE-AC06-76RLO 1830. Contact David Feller or Karen Schuchardt for further information.

${ }^{\dagger}$ P. Lazzeretti, R. Zanasi (University of Modena, 1980) with additional routines for evaluation and plotting of current density by E. Steiner and P. W. Fowler, R. W. A. Havenith and A. Soncini. 


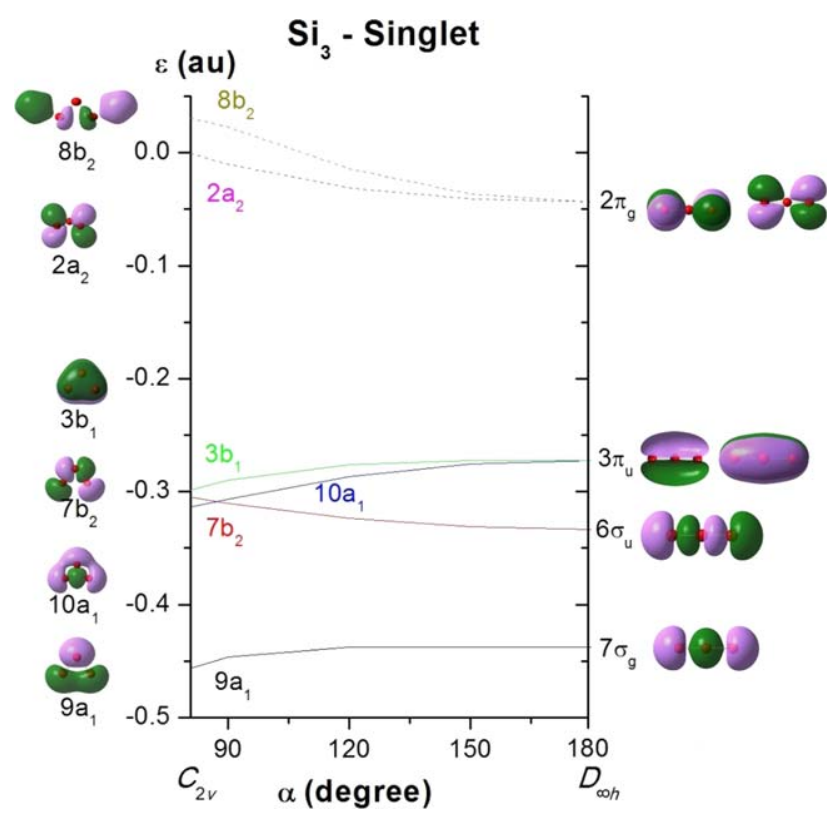

Figure 1. The Walsh diagram of the singlet $\mathrm{Si}_{3}$. Orbital energies are obtained using HF/aug-cc-pvTZ wavefunctions.

that it is cyclic in both low- and high-spin states, which basically differs from the linear homologue $C_{3}$. For the purpose of comprehension, let us briefly mention the optimized geometries of both states (values at $(\mathrm{U}) \mathrm{CCSD}(\mathrm{T})$ /aug-cc-pVQZ). The singlet state is an isosceles triangle $\left(C_{2 v},{ }^{1} A_{1}\right)$ with a distance of $2.19 \AA$ and an apex angle $\alpha=80.6^{\circ}$. The triplet state is an equilateral triangle $\left(D_{3 \mathrm{~h}},{ }^{3} \mathrm{~A}_{2}^{\prime}\right)$ with a bond length of $2.29 \AA$. The singlet parameters are comparable to experimental microwave data. ${ }^{[12]}$

To probe further this basic feature, we first perform a qualitative analysis of the electron distribution in both linear and cyclic forms. The corresponding molecular orbital (MO) correlation is well known as the Walsh diagram. ${ }^{[44]}$ Figure 1 displays the Walsh diagram of singlet $\mathrm{Si}_{3}$ and Figure 2 that of triplet $\mathrm{Si}_{3}$ obtained from a ROHF wavefunction.

The linear singlet ${ }^{1} \Sigma_{\mathrm{g}}^{+}$of $\mathrm{Si}_{3}$ is characterized as a secondorder saddle point with a degenerate $\pi_{\mathrm{u}}$ bending mode. As in any linear triatomic structure $X_{3}$, on angular motion (bending) each degenerate $\pi$ orbital splits into two components. Accordingly, the doubly degenerate $\pi_{\mathrm{u}}$ orbital (in $D_{\infty \mathrm{h}}$ point group) splits into one $a_{1}$ and one $b_{1}$ orbital (in $C_{2 v}$ ), the former component being lower in energy.

As seen in Figure 1, in its linear singlet state ${ }^{1} \Sigma_{\mathrm{g}}^{+}\left[\ldots\left(7 \sigma_{\mathrm{g}}\right)^{2}\right.$ $\left.\left(6 \sigma_{\mathrm{u}}\right)^{2}\left(3 \pi_{\mathrm{u}}\right)^{4}\left(2 \pi_{\mathrm{g}}\right)^{0}\right]$, the highest occupied molecular orbital (HOMO) of $\mathrm{Si}_{3}$ is the $3 \pi_{\mathrm{u}}$ orbital, and the low-energy location of its $a_{1}$ component on bending appears to be a dominant stabilizing factor (cf., Fig. 1). The $b_{1}$ component is also stabilized (becoming thus the $3 b_{1}$ orbital of cyclic $\mathrm{Si}_{3}$ ) but at a lesser extent. The resulting $10 a_{1}$ orbital corresponds to a new cyclic $\sigma$-bond, whereas the $3 b_{1}$ orbital is a cyclic $\pi$-bond.

The doubly degenerate $\pi_{\mathrm{g}}$ orbital is expected to split into one $a_{2}$ and one $b_{2}$ representation of $C_{2 v}$ point group with the former component being lower in energy. However, in $\mathrm{Si}_{3}$ this orbital corresponds to its LUMO, and as a consequence, its bending splitting is not important. Overall, as $\mathrm{Si}_{3}$ bends, the singlet state ${ }^{1} A_{1}\left[\ldots\left(10 a_{1}\right)^{2}\left(7 b_{2}\right)^{2}\left(3 b_{1}\right)^{2}\left(11 a_{1}\right)^{0}\right]$ is getting stabilized due to formation of new $\sigma$ and $\pi$ bonds (Fig. 1). In the low-spin state, the linear ${ }^{1} \Sigma_{\mathrm{g}}^{+}$of $\mathrm{Si}_{3}$ is located at about $67 \mathrm{~kJ} /$ mol above the ${ }^{1} A_{1}$ cycle (CCSD(T)/CBS value). In other words, the singlet state is strongly stabilized following a bending of the $\mathrm{Si}-\mathrm{Si}-\mathrm{Si}$ skeleton.

In the triplet linear $\mathrm{Si}_{3}$ whose orbital configuration is ${ }^{3} \Pi_{\mathrm{u}}$ [... $\left(7 \sigma_{\mathrm{g}}\right)^{2}\left(3 \pi_{\mathrm{u}}\right)^{4}\left(6 \sigma_{\mathrm{u}}\right)^{1}\left(2 \pi_{\mathrm{g}}\right)^{1]}$, the $\pi_{\mathrm{g}}$ orbital is now singly occupied, and its evolution on angular motion implies a significant contribution. Following bending, the unpaired $\sigma_{\mathrm{u}}$ orbital is again destabilized, whereas the other unpaired $\pi_{\mathrm{g}}$ orbital is stabilized. The paired orbitals $\sigma_{\mathrm{g}}$ and $\pi_{\mathrm{u}}$ in particular the $\sigma_{\mathrm{g}}$, turn out to significantly be stabilized following bending (Fig. 2), and this likely constitutes the main contribution to the stabilization of the cyclic triplet $\mathrm{Si}_{3}$. Let us note that as the linear $\mathrm{Si}_{3}$ bends yielding a $C_{2 v}$ structure, a full occupation of either the $b_{1}$ (formed from $\pi_{\mathrm{u}}$, leading to $a{ }^{3} B_{2}$ state) or the $b_{2}$ orbital (formed from $\pi_{\mathrm{g}}$, yielding $\mathrm{a}^{3} \mathrm{~B}_{1}$ state) is the main event. The ${ }^{3} B_{2}\left[\ldots\left(3 b_{1}\right)^{2}\left(7 b_{2}\right)^{1}\left(11 a_{1}\right)^{1}\right]$ state consistently becomes lower in energy and finally results in the ${ }^{3} A_{2}^{\prime}$ state $\left[\ldots\left(5 a_{1}^{\prime}\right)^{2}\right.$ $\left.\left(2 \mathrm{a}_{2}^{\prime \prime} \mathrm{a}_{2}^{\prime \prime}\right)^{2}\left(6 \mathrm{e}^{\prime}\right)^{2}\right]$ under $D_{3 \mathrm{~h}}$ symmetry.

The linear ${ }^{3} \Pi_{\mathrm{u}}$ state of $\mathrm{Si}_{3}$ is characterized as a first-order saddle point with an imaginary frequency for the $\pi_{\mathrm{u}}$ bending mode. It is much higher in energy than the corresponding singlet linear, as the relevant ${ }^{1} \Sigma_{\mathrm{g}}{ }^{+}-{ }^{3} \Pi_{\mathrm{u}}$ energy gap of linear $\mathrm{Si}_{3}$ amounts to about $140 \mathrm{~kJ} / \mathrm{mol}$ (CCSD(T)/CBS value). The linear ${ }^{3} \Pi_{u}$ state is also much higher in energy than the cyclic ${ }^{3} A_{2}^{\prime}$ state $(210 \mathrm{~kJ} / \mathrm{mol}$ using $\operatorname{CCSD}(\mathrm{T}) / \mathrm{CBS})$, thus suggesting that the triplet $\mathrm{Si}_{3}$ is also not likely to undergo inversion process.

In summary, the bending mode of $\mathrm{Si}_{3}$ splits the degenerate $\pi \mathrm{MO}$ of the linear form, and lowers the resulting $\sigma$ component, and thereby strongly stabilizes the cyclic form, in particular in its triplet state.

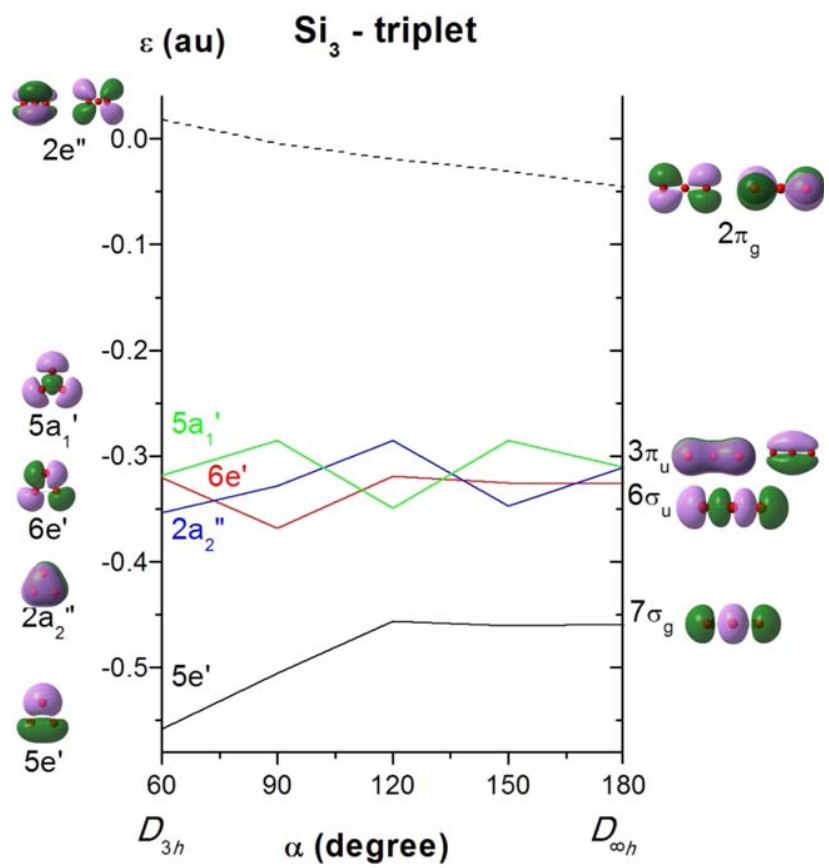

Figure 2. The Walsh diagram of the triplet $\mathrm{Si}_{3}$. Energies of the orbitals are obtained using ROHF/aug-cc-pvTZ wavefunctions. 
Table 1. Singlet-triplet energy gap $\left(\Delta E_{\mathrm{ST}}\right)$ of $\mathrm{Si}_{3}$ calculated using different DFT and wavefunction (WF)-based methods.

\begin{tabular}{|lr|} 
Method & $\Delta E_{S T}(\mathrm{~kJ} / \mathrm{mol})$ \\
\hline DFT: B3LYP & -6.9 \\
BLYP & 1.3 \\
B3P86 & -14.8 \\
BP86 & -8.0 \\
B3PW91 & -16.5 \\
BPW91 & -11.2 \\
PBEPBE & -12.4 \\
TPSSH & -17.5 \\
M06 & -0.5 \\
M06L & -16.3 \\
WF: G1 & 18.0 \\
G2 & 14.9 \\
G3 & 3.7 \\
G3B3 & 4.1 \\
G4 & 4.2 \\
MP2/aug-cc-pVTZ & 4.3 \\
MP2/aug-cc-pVQZ & 6.3 \\
CASSCF(12,12)/ANO-L & 19.2 \\
CASSCF(12,12)/aug-cc-pVQZ & 19.2 \\
CASPT2(12,12)/ANO-L & -2.2 \\
CASPT2(12,12)/ANO-L & -2.0 \\
CCSD(T)/aug-cc-pV(D + d)Z & 0.3 \\
CCSD(T)/aug-cc-pV(T + d)Z & 0.4 \\
CCSD(T)/aug-cc-pV(Q + d)Z & 0.3 \\
CCSD(T)/aug-cc-pV(5 + d)Z & 0.5 \\
CCSD(T)/aug-cc-pV(6 + d)Z & 0.5 \\
CCSD(T)/CBS(D,T,Q) & 0.6 \\
CCSD(T)/CBS(Q,5) & 0.6 \\
CCSD(T)/CBS(5,6) & 0.6 \\
CCSD(T)/CBS(Q,5,6) & 0.6 \\
CCSD(T)/aug-cc-pwCVQZ & 0.4 \\
CCSD(T)/aug-cc-pwCV5Z & 0.3 \\
CCSDT/aug-cc-pV(T + d)Z & -1.3 \\
CCSDT/aug-cc-pV(Q + d)Z & -0.7 \\
CCSDTQ/ aug-cc-pV(D + d)Z & 1.7 \\
CCSDTQ/cc-pV(T + d)Z & 0.6 \\
\hline
\end{tabular}

Further evaluation of the singlet-triplet separation of $\mathrm{Si}_{3}$

As mentioned above, both ${ }^{1} \mathrm{~A}_{1}$ and ${ }^{3} \mathrm{~A}_{2}^{\prime}$ states of $\mathrm{Si}_{3}$ have been found to be close in energy. Using both G4 and CCSD(T)/CBS energies, we obtained a gap of $\sim 2 \mathrm{~kJ} / \mathrm{mol}$ in favor of the lowspin state. ${ }^{[26]}$ However, the calculated total TAE of the latter was found with a deviation of $\sim 13-19 \mathrm{~kJ} / \mathrm{mol}$ with respect to a previous experimental determination. Both computed values of $\mathrm{TAE}\left(\mathrm{Si}_{3}\right)=724$ (G4) and $718 \mathrm{~kJ} / \mathrm{mol}$ (CBS) are in fact overestimated as compared with the available experimental result of $705 \pm 16 \mathrm{~kJ} / \mathrm{mol}$, even though both are close to the upper limit of the experimental error margin. Such a deviation is larger than the expected error bars of the methods used, and it is rather large for the S-T energy gap considered here. Therefore, we would determine again this quantity using some additional methods. As for a further test, results obtained using DFT with the most common functionals are also given. Table 1 summarizes the calculated singlet-triplet gap of $\mathrm{Si}_{3}$.

The first additional wavefunction-based method used is the conventional multiconfigurational method. The energies of both neutral $\mathrm{Si}_{3}$ clusters in the lowest singlet and triplet states are obtained using the complete active space CASSCF and the subsequent second-order perturbation theory CASPT2 methods with different basis sets including the ANO-L, aug-ccpVTZ, and aug-cc-pVQZ sets. Four valence orbitals ( $3 s$ and $3 p$ ) of each silicon atom are included in the active space. The active space is thus composed of 12 electrons in 12 orbitals, referred to hereafter as $\operatorname{CASSCF}(12,12)$ and $\operatorname{CASPT2}(12,12)$. All these calculations are performed using MOLCAS 7.6 suite of program $^{[37,45]}$ at the $(\mathrm{U}) \mathrm{CCSD}(\mathrm{T}) /$ aug-cc-pVQZ optimized geometries of both species mentioned above.

CASSCF $(12,12)$ computations on $\mathrm{Si}_{3}$ provide us with a gap of $19.2 \mathrm{~kJ} / \mathrm{mol}$ in favor of the singlet state, whereas the subsequent CASPT2 energies reverse the energy ordering pointing out that the triplet state is now at $\sim-2.0 \mathrm{~kJ} / \mathrm{mol}$ below the singlet counterpart, irrespective of the basis set used. The weights of the leading Hartree-Fock references in the CASSCF wavefunctions amount to 0.83 and 0.84 for the singlet and triplet $\mathrm{Si}_{3}$ states, respectively. Although the latter treatment tends to prefer low-spin states, the triplet state turns out to be favored by CASPT2 method. ${ }^{[46]}$ Let us note that the single reference second-order perturbation theory prefers the singlet state by up to $\sim 4.3 \mathrm{~kJ} / \mathrm{mol}$ (MP2/aug-cc-pVTZ, cf., Table 1).

We also extend the coupled-cluster theory computations by extending the one-electron basis sets to the aug-cc-pV6Z and aug-cc-pV $(6+d) Z$ basis sets (using (U)CCSD(T)/aug-cc-pVQZ optimized geometries), where $d$ stands for a set of tight $d$ functions. It is well known that diffuse functions have very small exponents and decay slowly with distance from the nuclei, tight $d$-functions having high exponents. The latter are added to improve the Hartree-Fock energies of the secondrow atoms due to a core polarization effect. Accordingly, the cc-pV $(n+d) Z$ sets exhibit a smooth progression in the M-shell d-exponents and include additional high exponent, L-shell $d$-functions to describe core polarization, and inner valence correlation effects. ${ }^{[47]}$ To address further the core-valence (CV) correlation corrections, we also consider the aug-cc-pwCVnZ ( $n=\mathrm{Q}$ and 5 ) basis sets specially optimized for this parameter. In the latter sets, the $(2 s, 2 p)$ core electrons are used for variable occupancy. The use of core electrons in the calculation of correlation energy tends to reduce the separation gap.

When using the coupled-cluster theory with full triple excitations CCSDT along with the aug-cc-pV $(T+d) Z$ and aug-cc$\mathrm{pV}(\mathrm{Q}+\mathrm{d}) \mathrm{Z}$ basis sets, and based on CCSDT/aug-cc-pV $(T+d) Z$

\begin{tabular}{|c|c|c|}
\hline & Singlet & Triplet \\
\hline $\begin{array}{l}\mathrm{TAE}_{\mathrm{e}} \mathrm{CCSD}(\mathrm{T}) /(\text { aug-cc-pV } \\
\quad(6+\mathrm{d}) \mathrm{Z} \text {, aug-cc-pV }(5+\mathrm{d}) \mathrm{Z})\end{array}$ & 173.52 & 173.17 \\
\hline Core (aug-cc-pwCV5Z) & 0.80 & 0.90 \\
\hline Scalar relativistic & -0.43 & -0.47 \\
\hline Spin Orbit & -1.275 & -1.275 \\
\hline ZPE (anharmonic) ${ }^{[\mathrm{b}]}$ & -1.80 & -1.66 \\
\hline CCSDTQ-CCSD $(T)$ & 1.12 & 1.09 \\
\hline $\mathrm{TAE}_{\mathrm{OK}}$ & 171.94 & 171.76 \\
\hline \multicolumn{3}{|c|}{$\begin{array}{l}\text { [a] Method implemented of the CFOUR program (Ref. [34]). [b] The fun- } \\
\text { damental vibrational frequencies of the singlet state are 180, 524, and } \\
549 \mathrm{~cm}^{-1} \text { whereas those of the triplet state are: } 324,325 \text {, and } \\
502 \mathrm{~cm}^{-1} \text {, both results obtained at the CCSD }(T) / c c-p V(T+d) Z \text { level. }\end{array}$} \\
\hline
\end{tabular}




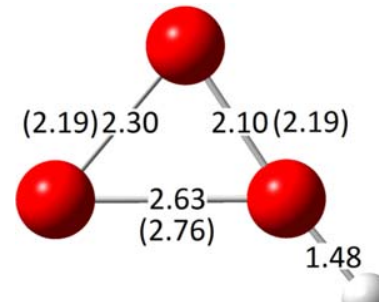

$\mathrm{Si}_{3} \mathrm{H}^{+}\left({ }^{1} \mathrm{~A}^{\prime}\right) \mathbf{0 . 0}$

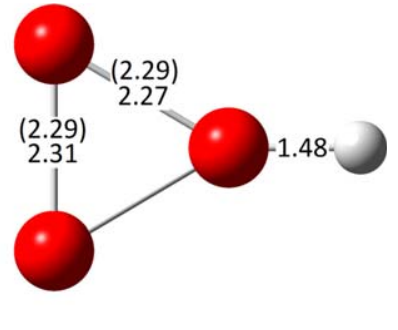

$\mathrm{Si}_{3} \mathrm{H}^{+}\left({ }^{3} \mathrm{~B}_{2}\right) 9.0$

Figure 3. Shapes, selected bond distances (angstrom, $\operatorname{CCSD}(T) / a u g-c c-$ $\mathrm{pVQZ})$, relative energy $(\mathrm{CCSD}(\mathrm{T}) / \mathrm{CBS}, \mathrm{kJ} / \mathrm{mol})$ of the protonated silicon trimer $\mathrm{Si}_{3} \mathrm{H}^{+}$in both singlet and triplet states. In parentheses are the distances in $\mathrm{Si}_{3}$ having the same spin state. [Color figure can be viewed in the online issue, which is available at wileyonlinelibrary.com.]

geometries, the S-T energy gap amounts to 1.3 and $0.7 \mathrm{~kJ} / \mathrm{mol}$, respectively, but now in favor of the triplet state. Following geometry optimizations at the CCSDT/aug-cc-pV $(T+d) Z$ level, the $\mathrm{Si}-\mathrm{Si}$ distances are calculated to be $2.193 \AA$ for the singlet and $2.298 \AA$ for the triplet. Including a ZPE correction of 0.6 $\mathrm{kJ} / \mathrm{mol}$, the S-T energy gap is now $\sim 1.3 \mathrm{~kJ} / \mathrm{mol}$ in favor of the triplet state. The ZPE amount to 7.5 and $7.0 \mathrm{~kJ} / \mathrm{mol}$ for the singlet and triplet states, respectively, (values obtained using the UHF-CCSD(T)/cc-pV(T $+\mathrm{d}) \mathrm{Z}$ harmonic and anharmonic vibrational frequencies as implemented in CFOUR.

To calibrate further the methods, we also compute the energies of both states using the full CCSDTQ method, in conjunction with the aug-cc-pV(D+d)Z and cc-pV(T $+d) Z$ basis sets. At the latter levels, the singlet is more stable by 1.7 and 0.6 $\mathrm{kJ} / \mathrm{mol}$, respectively. In Table 2, we present the TAE computed for both isomers including all the corrections necessary to reach a few $\mathrm{kJ} / \mathrm{mol}$ accuracy. Our best estimate indicates that, at $0 \mathrm{~K}$, the singlet state is $0.8 \mathrm{~kJ} / \mathrm{mol}$ more stable than the triplet.

Table 1 also points out that most common DFT functionals tend to largely favor the triplet state, except for the BLYP and M06 functionals that yield small energy gaps. However, the pure functional BLYP predicts a singlet ground state for $\mathrm{Si}_{3}$. The present results point out that the current DFT functionals are not able to attain high accuracy results for the excited states of atomic clusters, perhaps the $\mathrm{S}-\mathrm{T}$ gap of $\mathrm{Si}_{3}$ can be used as another useful benchmark for DFT methods.

The energy gaps obtained using wavefunction-based methods such as the composite G3 and G4 approaches and coupled-cluster theories agree well with each other within the chemical accuracy of $\pm 8 \mathrm{~kJ} / \mathrm{mol}$ or $\pm 0.1 \mathrm{eV}$. The results obtained by CASSCF/CASPT2 are not surprising as this method often fails to predict the singlet-triplet gaps of small molecules.

Overall, although the identity of the ground state of $\mathrm{Si}_{3}$ remains uncertain, even the singlet is marginally lower in energy when using the high accuracy wavefunction-based methods, the singlet-triplet separation gap is now reduced to about $\sim 0.5-1.0 \mathrm{~kJ} / \mathrm{mol}$. Thus, a small error on the different correction terms to the total energies, for example, the ZPEs, could induce a change in the energy ordering. In this context,

we would conclude that at their vibrational ground state, both singlet and triplet states of $\mathrm{Si}_{3}$ can be regarded as degenerate.

Let us now consider the crossing between both states. As the main geometrical parameter determining the spin state of $\mathrm{Si}_{3}$ is the apex angle $\alpha=\mathrm{SiSiSi}$, an intersystem crossing along this coordinate is possible. To probe this possibility, we scan the potential energies as a function of this parameter using (U)CCSD(T)/auc-cc-pVTZ energies. At each bond angle value, the distances are optimized. It turns out that both singlet and triplet states attain a similar energy at a value of $\alpha=\sim 68^{\circ}$, and this S-T crossing point is being $\sim 16$ and $\sim 17 \mathrm{~kJ} / \mathrm{mol}$ above the singlet and triplet states, respectively. In view of the fact that this point is geometrically close to the triplet equilibrium structure $\left(\alpha=60^{\circ}\right)$, a crossing between both high- and low-spin states of $\mathrm{Si}_{3}$ appears to be quite likely following a large amplitude bending of the triplet. Accordingly, a S-T degeneracy and a possible quenching of the high-spin state on bending could imply some significant consequences on the spectroscopic observation of $\mathrm{Si}_{3}$. However, such a treatment goes beyond the scope of the present work.

Effect of protonation and attachment of alkali metal cations on the singlet-triplet energy gap

Protonation. Proton is the smallest and hardest ion, and the proton affinity (PA) is in addition an important thermochemical parameter. Protonation often induces large changes in the geometrical and electronic structure of a substrate. It is known that the triplet ground state $\left({ }^{3} \mathrm{P}\right)$ of the $\mathrm{Si}$ atom is completely quenched on protonation. The protonated form $\mathrm{SiH}^{+}$indeed exhibits a closed-shell singlet state $\left({ }^{1} \Sigma^{+}\right) \cdot{ }^{[48]}$ On the contrary, the triplet manifold remains the ground state of either the diatomic silicon $\left(\mathrm{Si}_{2},{ }^{3} \mathrm{\Sigma}_{\mathrm{g}}{ }^{+}\right)$or its protonated form $\left(\mathrm{Si}_{2} \mathrm{H}^{+},{ }^{3} \mathrm{~B}_{1}\right)$. In the latter, the proton is attached to the $\mathrm{Si}-\mathrm{Si}$ bond giving rise to a bridged form. Following protonation, the singlet-triplet gap is, however, reduced from $60 \mathrm{~kJ} / \mathrm{mol}$ in $\mathrm{Si}_{2}$ to $40 \mathrm{~kJ} / \mathrm{mol}$ in $\mathrm{Si}_{2} \mathrm{H}^{+}$(CCSD(T)/CBS).

Figure 3 displays the protonated structures $\mathrm{Si}_{3} \mathrm{H}^{+}$in both singlet and triplet states. The low-spin state is calculated to be favored by $9 \mathrm{~kJ} / \mathrm{mol}$ in the protonated form (CCSD(T)/CBS). In the singlet state, the proton is attached to a terminal $\mathrm{Si}$ atom with a nearly linear $\mathrm{Si}-\mathrm{Si}-\mathrm{H}$ framework. Parameters of the $\mathrm{Si}_{3}$

Table 3. Proton affinity (PA at $0 \mathrm{~K}, \mathrm{~kJ} / \mathrm{mol}$ ) of $\mathrm{Si}_{3}$ calculated using different $\mathrm{MO}$ methods with respect to the same electronic state of the protonated form $\mathrm{Si}_{3} \mathrm{H}^{+}$

\begin{tabular}{|c|c|c|}
\hline Method & PA (Singlet) & PA (Triplet) \\
\hline G4 & 820 & 809 \\
\hline $\operatorname{CCSD}(T) /$ aug-cc-pV(D $+d) Z$ & 820 & 812 \\
\hline $\operatorname{CCSD}(T) /$ aug-cc-pV $(T+d) Z$ & 826 & 817 \\
\hline $\operatorname{CCSD}(\mathrm{T}) /$ aug-cc-pV $(\mathrm{Q}+d) \mathrm{Z}$ & 826 & 818 \\
\hline $\operatorname{CCSD}(T) /$ aug-cc-pV $(5+d) Z$ & 826 & 817 \\
\hline $\operatorname{CCSD}(T) /$ aug-cc-pV $(6+d) Z$ & 825 & 817 \\
\hline $\operatorname{CCSD}(\mathrm{T}) / \mathrm{CBS}(\mathrm{D}, \mathrm{T}, \mathrm{Q})$ & 826 & 818 \\
\hline $\operatorname{CCSD}(T) / \operatorname{CBS}(Q, 5)$ & 826 & 817 \\
\hline $\operatorname{CCSD}(\mathrm{T}) / \operatorname{CBS}(5,6)$ & 825 & 816 \\
\hline $\operatorname{CCSD}(\mathrm{T}) / \mathrm{CBS}(\mathrm{Q}, 5,6)$ & 825 & 817 \\
\hline
\end{tabular}



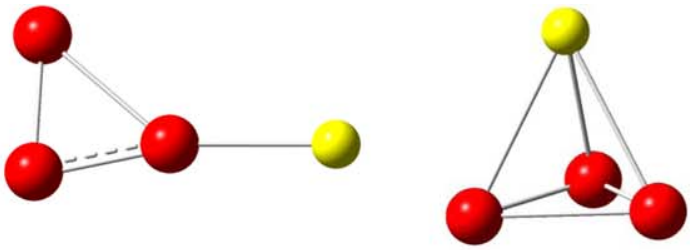

Li-s-1 ( $\left.{ }^{1} \mathrm{~A}, C_{l}\right)$

0

Li-s-2 ( $\left.{ }^{1} \mathrm{~A}, C_{l}\right)$

16

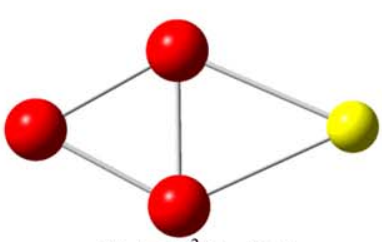

Li-t-1 $\left({ }^{3} \mathrm{~B}_{2}, C_{2 v}\right)$

26

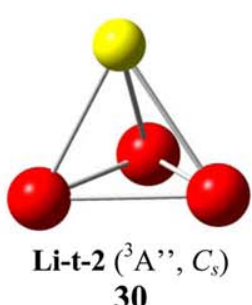

30

a) $\mathrm{Si}_{3} \mathrm{Li}^{+}$cation

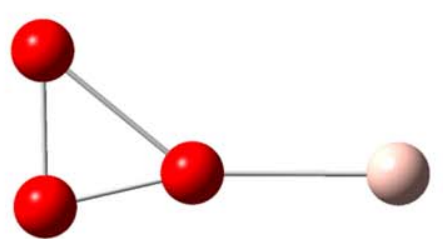

Na-s-1 $\left({ }^{1} \mathrm{~A}^{\prime}, C_{s}\right)$

0

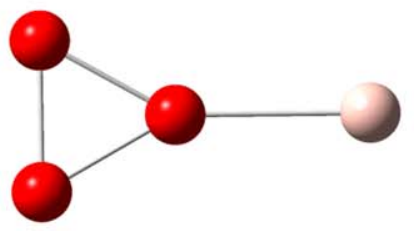

Na-t-1 $\left({ }^{3} \mathrm{~B}_{2}, C_{2 v}\right)$

10

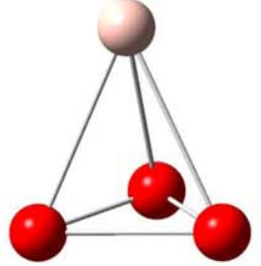

Na-s-2 $\left({ }^{1} \mathrm{~A}, C_{l}\right)$

13

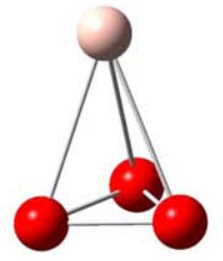

Na-t-2 ( $\left.{ }^{3} \mathrm{~A}^{\prime},, C_{s}\right)$

24

b) $\mathrm{Si}_{3} \mathrm{Na}^{+}$Cation

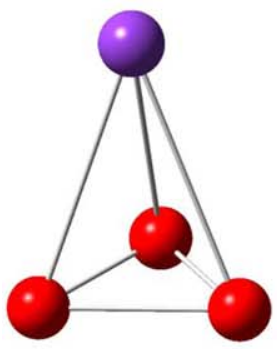

K-s-1 ( $\left.{ }^{1} \mathrm{~A}^{\prime}, C_{s}\right)$

3

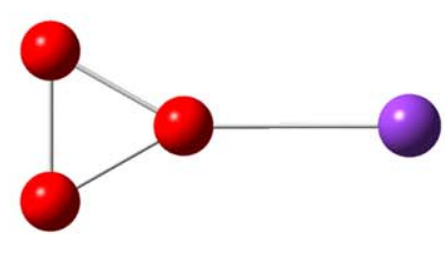

K-t-1 $\left({ }^{3} \mathrm{~A}^{\prime}, C_{s}\right)$

0

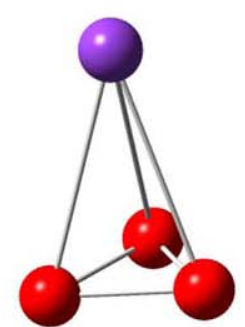

K-t-2 $\left({ }^{3} \mathrm{~A}, C_{l}\right)$

11

\section{c) $\mathrm{Si}_{3} \mathrm{~K}^{+}$Cation}

Figure 4. Shapes, electronic state, relative energy (G4, kJ/mol) of the $\mathrm{Si}_{3} \mathrm{M}^{+}$cations, with $\mathrm{M}=\mathrm{Li}^{+}$, $\mathrm{Na}^{+}$, and $\mathrm{K}^{+}$, in both singlet and triplet states. $[\mathrm{Color}$ figure can be viewed in the online issue, which is available at wileyonlinelibrary.com.]

ring are only slightly changed. In the triplet state, protonation occurs at a $\mathrm{Si}$ atom rather that at a $\mathrm{Si}-\mathrm{Si}$ bond such as in the case of $\mathrm{Si}_{2}$, and marginally modifies the cyclic framework.
All the $\operatorname{CCSD}(\mathrm{T}) / \mathrm{CBS}$ values for the $\mathrm{PA}\left(\mathrm{Si}_{3}\right)$ are internally consistent (Table 3). This is computed as $\mathrm{PA}\left(\mathrm{Si}_{3}\right)=825 \mathrm{~kJ} / \mathrm{mol}$ (value at $0 \mathrm{~K}$, the value at $298 \mathrm{~K}$ being $830 \mathrm{~kJ} / \mathrm{mol}$ for the 
singlet state). This parameter is reduced as compared with the values of 838 and $847 \mathrm{~kJ} / \mathrm{mol}$ for $\mathrm{Si}_{2}$ and $\mathrm{Si}$, respectively, using the same level. At the $\mathrm{G} 4$ level, the calculated PAs amount to $820\left(\mathrm{Si}_{3}\right), 839\left(\mathrm{Si}_{2}\right)$, and $848(\mathrm{Si}) \mathrm{kJ} / \mathrm{mol}$. The value for the Si atom compares only fairly with the available experimental result of $833 \mathrm{~kJ} / \mathrm{mol}\left(\mathrm{PA}(\mathrm{Si})=837 \mathrm{~kJ} / \mathrm{mol}\right.$ at $\left.298 \mathrm{~K}^{[48]}\right)$. Thus, the basicity of Si clusters tends to decrease with the increasing cluster size. The PA values for the triplet $\mathrm{Si}_{3}$, that are evaluated with respect to triplet $\mathrm{Si}_{3} \mathrm{H}^{+}$to keep the spin manifold, are also listed in Table 3. They are also consistent and smaller than the PAs for singlet state, in view of the larger S-T gap of the protonated form (cf., Fig. 3).

Overall, it can be concluded that protonation seems to favor the low-spin ground state, but the corresponding singlet-triplet separation remains small.

Attachment of the $\mathrm{Li}^{+}, \mathrm{Na}^{+}$, and $\mathrm{K}^{+}$cations. We now consider the effects of alkali cations. Figure 4 displays the lowest-lying structures of the $\mathrm{Si}_{3} \mathrm{M}^{+}$cations in both singlet and triplet states, with $\mathrm{M}=\mathrm{Li}, \mathrm{Na}$, and $\mathrm{K}$. For this series, only $\mathrm{G} 4$ values are considered. In contrast to the protonation discussed above, attachment of the $\mathrm{M}^{+}$cation can now occur either in or out of the $\mathrm{Si}_{3}$ plane. The intrinsically longer bonds of the metal ions allow an effective interaction with the ring electrons at long distances. The $\mathrm{M}^{+}$attachment shows some similarities but also significant differences:

i. For $\mathrm{Li}^{+}$, both ways of addition are possible in both states. The in-plane addition occurs at one Si lone pair in the singlet state, giving a planar adduct Li-s-1, but on a $\mathrm{Si}-\mathrm{Si}$ bond in the triplet yielding Li-t-1. The out-ofthe-plane addition involves the whole $\mathrm{Si}_{3}$ ring yielding a tetrahedral adduct Li-s-2 and Li-t-2. In both states, the in-plane attachment is more favorable. The planar singlet adduct Li-s-1 turns out to be more stable than the other forms (Fig. 4), being $26 \mathrm{~kJ} / \mathrm{mol}$ below the triplet counterpart Li-t-1. As for a comparison, in the analogue germanium cluster $\mathrm{Ge}_{3} \mathrm{Li}^{+}$, the singlet state is also preferred over the triplet counterpart. ${ }^{[49]}$ In other words, a $\mathrm{Li}^{+}$ attachment tends to stabilize the low-spin state of the resulting cluster cation.

ii. A similar behavior can be noticed for $\mathrm{Na}^{+}$addition. The main difference with respect to $\mathrm{Li}^{+}$addition is that the in-plane addition occurs at a Si lone pair in both singlet Na-s-1 and triplet Na-t-1. Although the singlet Na-s-1 is again preferred, the relevant S-T gap is now reduced to about $10 \mathrm{~kJ} / \mathrm{mol}$ (Fig. 4)

iii. Attachment of the heavier $\mathrm{K}^{+}$ion leads to a quite different structural landscape. In the singlet state, the in-plane approach no longer exists. In addition, the lone pairattached planar triplet K-t-1 becomes now slightly, by $\sim 3 \mathrm{~kJ} / \mathrm{mol}$, more stable than the tetrahedral singlet $\mathbf{K}-\mathbf{s}$ 1. As in the $\mathrm{Li}$ and $\mathrm{Na}$ cases, the tetrahedral singlet remains more stable than the corresponding triplet. Overall, the heavier $\mathrm{K}^{+}$ion undergoes interaction with a Si lone pair, and favors the high-spin state.
The metal cation affinities (MCA) of $\mathrm{Si}_{3}$ are calculated using the G4 method. The MCA are, as expected, far smaller than the PA. The MCA can be considered as a measure of the degree of stabilization attained by the cluster on metal attachment. In both electronic states, the MCA is consistently decreased in going down the Periodic Table. In the singlet manifold, the MCA is reduced roughly by one third in going successively from $\mathrm{Li}^{+}(108 \mathrm{~kJ} / \mathrm{mol})$ to $\mathrm{Na}^{+}(79 \mathrm{~kJ} / \mathrm{mol})$ and then to $\mathrm{K}^{+}(37 \mathrm{~kJ} / \mathrm{mol})$.

The $\mathrm{Li}^{+}$affinity ( $\mathrm{LiCA}$ ) of $\mathrm{Si}_{3}$ of $108 \mathrm{~kJ} / \mathrm{mol}$ derived from Li-s1 (G4, Table 3) turns out to be identical with that of the diatomic $\mathrm{Si}_{2}\left(109 \mathrm{~kJ} / \mathrm{mol}\right.$ for the linear triplet $\left.\mathrm{Si}_{2} \mathrm{Li}^{+}\right)$, but both are substantially larger than the LiCA of the $\mathrm{Si}$ atom $(74 \mathrm{~kJ} / \mathrm{mol}$ with respect to the triplet $\mathrm{SiLi}^{+}$). The value for $\mathrm{Si}_{2}$ is of the same order of magnitude as the LiCA of the $\mathrm{Ge}_{2}$ dimer which was previously computed to be $103 \mathrm{~kJ} / \mathrm{mol}$ at the B3LYP/6$31++\mathrm{G}(\mathrm{d}, \mathrm{p})$ level. ${ }^{[50]}$

The $\mathrm{Na}^{+}(\mathrm{NaCA})$ and $\mathrm{K}^{+}$(KCA) affinities follow a similar pattern. The $\mathrm{NaCA}$ of $\mathrm{Si}, \mathrm{Si}_{2}$, and $\mathrm{Si}_{3}$ are computed to be 54,80 , and $79 \mathrm{~kJ} / \mathrm{mol}\left(\mathrm{Si}_{3}\right.$ via Na-s-1), respectively. The $\mathrm{KCA}$ of $\mathrm{Si}, \mathrm{Si}_{2}$, and $\mathrm{Si}_{3}$ amount to 34,50 , and $44 \mathrm{~kJ} / \mathrm{mol}$ (involving the triplet K-t-1), respectively. The rather low MCA of the Si atom is manifested in the corresponding long $\mathrm{Si}-\mathrm{M}$ bonds. The diatomic $\mathrm{SiNa}^{+}$and $\mathrm{SiK}^{+}$or triatomic $\mathrm{Si}_{2} \mathrm{Na}^{+}$and $\mathrm{Si}_{2} \mathrm{~K}^{+}$cations exhibit a high spin ground state. The triatomic cation also features a bridged form $\left(C_{2 v}\right)$. As expected, the $\mathrm{Si}-\mathrm{M}$ bond length vary significantly from $2.58,2.92$, to $3.58 \AA$ in going from the planar singlet $\mathrm{Si}_{3} \mathrm{Li}^{+}$Li-s-1 to $\mathrm{Si}_{3} \mathrm{Na}^{+}$Na-s-1 and tetrahedral triplet $\mathrm{Si}_{3} \mathrm{~K}^{+}$K-t-1. Geometry of the singlet $\mathrm{Si}_{3}$ moiety appears to be more distorted than that of the triplet one following cation attachment. Geometrical parameters of the $\mathrm{Si}_{3} \mathrm{M}^{+}$cations are given in the Supporting Information (Electronic Supplementary Information).

In summary, attachment of alkali metal cations to $\mathrm{Si}_{3}$ clearly results in a splitting of both low- and high-spin states, but the trend is not the same. The lighter cations tend to reinforce the low-spin state via strong ion-molecule interaction, whereas the heavier cation prefers the high spin manifold through much weaker interaction. This result suggests different ways of making larger structures using $\mathrm{Si}_{3}$ as building blocks. The $\mathrm{H}^{+}, \mathrm{Li}^{+}$, and $\mathrm{Na}^{+}$cations could be used as linkers for low-spin assemblies, whereas the heavier cation $\mathrm{K}^{+}$could induce high spin counterparts (such as $\left[\mathrm{Si}_{3}\left(\text { sbond) } \mathrm{K}^{+} \text {(sbond) } \mathrm{Si}_{3} \text { (sbond) } \mathrm{K}^{+}\right]_{n}\right.$ with larger magnetic moments.

Finally, we would predict the following alkali MCA, $\mathrm{LiCA}\left(\mathrm{Si}_{3}\right)=108 \pm 8 \mathrm{~kJ} / \mathrm{mol}, \mathrm{NaCA}\left(\mathrm{Si}_{3}\right)=79 \pm 8 \mathrm{~kJ} / \mathrm{mol}$, and $\mathrm{KCA}\left(\mathrm{Si}_{3}\right)=44 \pm 8 \mathrm{~kJ} / \mathrm{mol}$ (G4 values).

An analysis of the chemical bonding. In an attempt to gain further understanding of the effect of protonation and metal cation attachment, we analyze the electron distribution in $\mathrm{Si}_{3}$ and its cationic $\mathrm{Si}_{3} \mathrm{M}^{+}$forms. We first use the ELF technique to locate the whereabouts of electrons and thereby to identify the chemical bonding.

Figure 5 displays the ELF plots of $\mathrm{Si}_{3}$ in both electronic states. The ELF is a simple measure of the electron localization in a molecular system and thus gives information about the 


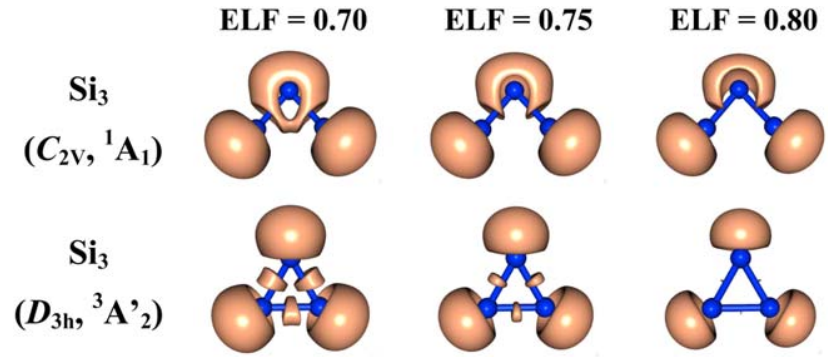

Figure 5. ELF isosurface plots of $\mathrm{Si}_{3}$ in both singlet and triplet states (B3LYP/6-311+g[d]) at different bifurcation values. [Color figure can be viewed in the online issue, which is available at wileyonlinelibrary.com.]

spaces of molecule, called basins, where electrons are likely to occupy. This method is useful to address localization domains which correspond to bonding or lone pairs. The bifurcation ELF values are always in a range of $[0,1]$ and are relatively large when the electrons are unpaired or formed into pairs with antiparallel spins. The zero flux surfaces of the ELF separate the electron density into basins, and thus help us to identify the core, bond, and lone pairs. The valence basins are characterized by their synaptic order, that is, the number of the core basins that share a common boundary surface with the valence basin. Monosynaptic basin represents a lone pair whereas disynaptic basin belongs to a covalent bond, and trisynaptic basin a three-centre bond. The number of electrons in a basin is determined by integration of electron distribution function over its region. Figure 5 thus displays localization domains given at high bifurcation values of $0.70-0.90$ of $\mathrm{Si}_{3}$ in both low- and high-spin states. This allows us to have a view on the electron concentrations.

Accordingly, the electron distribution in both states of the $\mathrm{Si}_{3}$ cluster differs somewhat from each other. In the triplet, three monosynaptic domains $\mathrm{V}(\mathrm{Si})$ and three disynaptic domains $\mathrm{V}(\mathrm{Si}, \mathrm{Si})$ can clearly be identified. Each of the lone pairs is occupied by $\sim 2.5$ electrons, and each $\mathrm{Si}-\mathrm{Si}$ bond by 1.5 electrons. In the singlet $\mathrm{Si}_{3}$, two monosynaptic basins $\mathrm{V}(\mathrm{Si})$ are present corresponding to lone pairs of the two terminal $\mathrm{Si}$ atoms, each being occupied by 2.4 electrons. One monosynaptic $\mathrm{V}(\mathrm{Si})$ and two disynaptic basins $\mathrm{V}(\mathrm{Si}, \mathrm{Si})$ are all centred around the central Si and practically form a large domain having $\sim 5.0$ electrons. In particular, a trisynaptic basin $\mathrm{V}(\mathrm{Si}, \mathrm{Si}, \mathrm{Si})$ with a population of $\sim 2.2$ electrons is located indicating a certain three-centre bond covering $\mathrm{Si}$ atoms.

In the $\mathrm{Si}_{3} \mathrm{M}^{+}$cations, a charge transfer is taken place from $\mathrm{Si}_{3}$ to the cation. The $\mathrm{M}$ atom becomes less positively charged, being +0.6 electrons for $\mathrm{Li},+0.8$ for $\mathrm{Na}$, and +0.7 for $\mathrm{K}$ (Mulliken populations). Figure 6 displays the ELF localization domains identified at bifurcation value of 0.90 of $\mathrm{Si}_{3} \mathrm{M}^{+}$in both low- and high-spin states. In the case of $\mathrm{Li}^{+}$, the singlet exhibits a basin between $\mathrm{Li}^{+}$and terminal $\mathrm{Si}(2)$ atom that confirms the existence of a $\mathrm{Si}-\mathrm{Li}$ bond. Population analysis points out that the $\mathrm{V}(\mathrm{Si} 2, \mathrm{Li})$ basin is occupied by 2.5 electrons which corresponds to the $\mathrm{V}(\mathrm{Si})$ basin of singlet $\mathrm{Si}_{3}$. Thus, the $\mathrm{Li}^{+}$ion uses its empty $2 s$ atomic orbital $(\mathrm{AO})$ to coordinate with a lone pair of the low spin $\mathrm{Si}_{3}$.

Two $\mathrm{V}(\mathrm{Si}, \mathrm{Li})$ basins are observed in triplet $\mathrm{Si}_{3} \mathrm{Li}^{+}$which is in line with the fact that the bridged $\mathrm{Li}^{+}$cation forms two $\mathrm{Si}-\mathrm{Li}$ bonds. The presence of disynaptic $\mathrm{V}(\mathrm{Si}, \mathrm{Li})$ basins of the high spin $\mathrm{Si}_{3} \mathrm{Li}^{+}$is related to lone pair basins of the triplet bare $\mathrm{Si}_{3}$. This arises from a simultaneous coordination of the empty $2 \mathrm{~s}$ $\mathrm{AO}$ of $\mathrm{Li}^{+}$with two lone pairs of triplet $\mathrm{Si}_{3}$. All the basins have electron populations larger than two electrons.

In both states of $\mathrm{Si}_{3} \mathrm{Na}^{+}$, only one basin located between $\mathrm{Na}^{+}$and $\mathrm{Si}$ atoms is observed in the ELF isosurface at bifurcation value of 0.90 . Electron population of the disynaptic $\mathrm{V}(\mathrm{Si}, \mathrm{Na})$ basin in both spin states of $\mathrm{Si}_{3} \mathrm{Na}^{+}$has a similar value of 2.5 electrons which is comparable to that of a lone pair basins in both the singlet and triplet $\mathrm{Si}_{3}$. As in the previous case, a $\mathrm{Si}-\mathrm{Na}$ bond of $\mathrm{Si}_{3} \mathrm{Na}^{+}$in both spin states can be established by coordination of the vacant $3 \mathrm{~s} \mathrm{AO}$ of $\mathrm{Na}^{+}$with a lone pair of the $\mathrm{Si}_{3}$.

In the case of $\mathrm{K}^{+}$, no basin is located in the region between $\mathrm{K}^{+}$and $\mathrm{Si}$ atoms in the ELF isosurface of singlet $\mathrm{Si}_{3} \mathrm{~K}^{+}$, because of the large $\mathrm{K}-\mathrm{Si}_{3}$ distance. Accordingly, the interaction energy discussed above is mainly provided by electrostatic attraction.
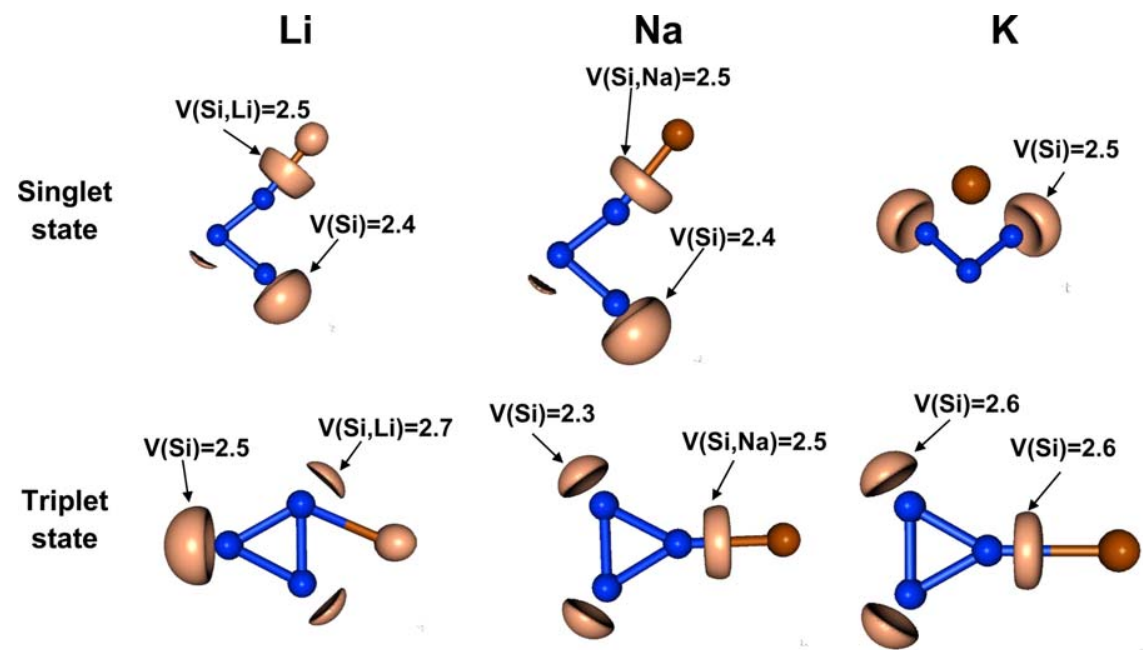

Figure 6. ELF isosurface plots of $\mathrm{Si}_{3} \mathrm{M}^{+}(\mathrm{M}=\mathrm{Li}, \mathrm{Na}$, and $\mathrm{K})$ in both singlet and triplet states $(\mathrm{B} 3 \mathrm{LYP} / 6-311+\mathrm{G}[\mathrm{d}])$ at bifurcation value ELF $=0.9$. [Color figure can be viewed in the online issue, which is available at wileyonlinelibrary.com.] 


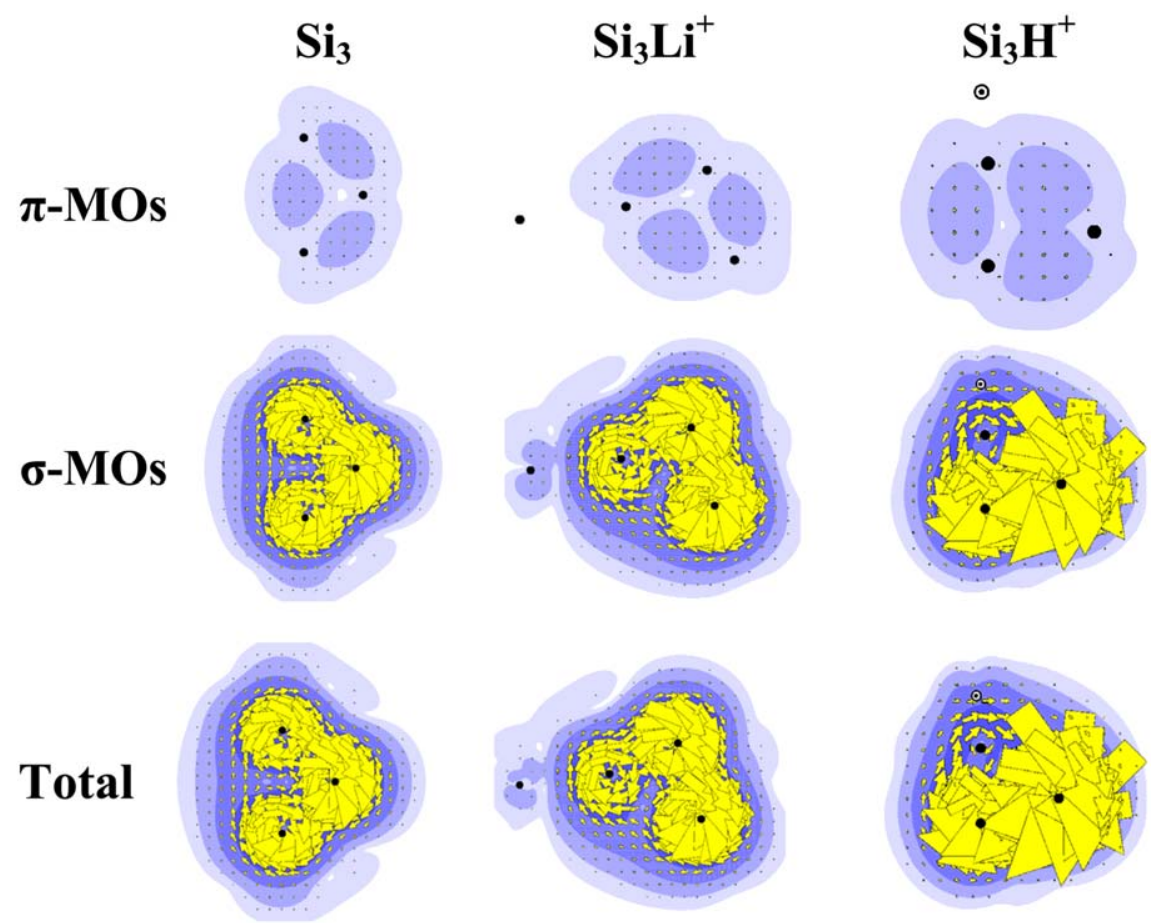

Figure 7. The maps of the $\pi, \sigma$ and total ring currents of $\mathrm{Si}_{3}, \mathrm{Si}_{3} \mathrm{Li}^{+}$, and $\mathrm{Si}_{3} \mathrm{H}^{+}$. [Color figure can be viewed in the online issue, which is available at wileyonlinelibrary.com.]

A localization domain of triplet $\mathrm{Si}_{3} \mathrm{~K}^{+}$exists between $\mathrm{K}^{+}$cation and $\mathrm{Si}$ atom. Population analysis indicates a population of 2.8 electrons for the $\mathrm{V}(\mathrm{Si}, \mathrm{K})$ basin, which is corresponding to that of $\mathrm{V}(\mathrm{Si})$ of triplet $\mathrm{Si}_{3}$.
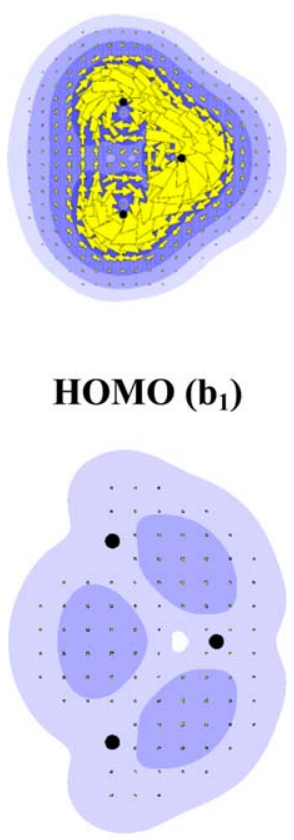

HOMO -2 (a $\left.a_{1}\right)$

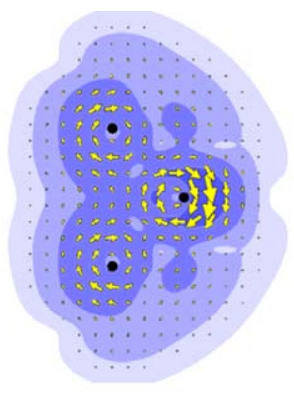

HOMO - $1\left(b_{2}\right)$

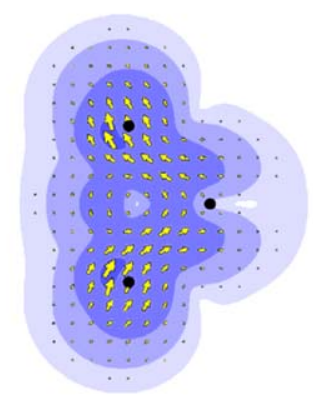

HOMO - $3\left(\mathbf{a}_{1}\right)$
Overall, attachment of $\mathrm{M}^{+}$cations to $\mathrm{Si}_{3}$ is taken place in both states by coordination of the vacant $\mathrm{ns} \mathrm{AO}$ of $\mathrm{M}^{+}$cation with a lone pair of $\mathrm{Si}_{3}$ partner. Such a coordination subsequently leads to large lengths of $\mathrm{M}-\mathrm{Si}$ bonds, and rather small effect of the cation $\mathrm{M}^{+}$on the $\mathrm{Si}_{3}$ moiety in both singlet and

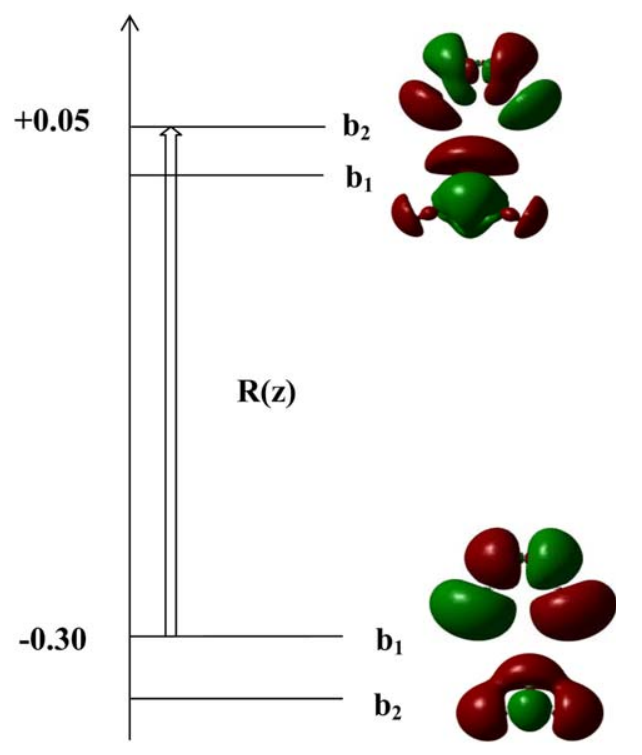

Figure 8. Contributions of the HOMOs to the ring currents of $\mathrm{Si}_{3}$, and the electronic transitions responsible for the magnetic properties of $\mathrm{Si}_{3}$. [Color figure can be viewed in the online issue, which is available at wileyonlinelibrary.com.] 
triplet spin states, and thereby only a small change of the singlet-triplet energy gap.

Ring current and aromaticity. One of the characteristics of electron distribution in cyclic compounds is the aromaticity. As silicon trimer has a cyclic form, an issue of interest thus concerns its eventual aromaticity. We now probe the aromaticity of this three-membered ring. It should be mentioned that while singlet-triplet separation is a quantitative thermochemical parameter, aromaticity is a qualitative index of the stability of a molecule. Although a certain relationship between both properties could exist, we could not investigate in the present work such a relationship as we only evaluate the aromaticity of the singlet state.

For this purpose, the ipsocentric model is an effective model which was used to evaluate aromaticity of planar compounds. ${ }^{[51]}$ In the framework of this model, an excitation from an occupied to an unoccupied molecular orbital can result in a contribution to the ring current which can be either diatropic, paratropic, or null. Accordingly, a diatropic current arises if the product of symmetries of occupied and unoccupied orbitals contains the in-plane translational symmetry. In an opposite case, a paratropic current results when the product of symmetries of occupied and unoccupied orbitals contains the inplane rotational symmetry. This rule is relatively simple for planar species.

The calculated ring current plots of the singlet $\mathrm{Si}_{3}$ and $\mathrm{Si}_{3} \mathrm{Li}^{+}$ are displayed in Figure 7. The electron densities can be partitioned in terms of $\sigma$ and $\pi$ MOs. Only one delocalized $\sigma$ MO is effective for the ring current, and the total current includes all core, $\pi$ and $\sigma$ MOs. In all cases, either the $\mathrm{Si}_{3}$ or the cation $\mathrm{Si}_{3} \mathrm{Li}^{+}, \pi$ electrons bring in small contribution to the total ring current. The $\sigma$ electrons of singlet $\mathrm{Si}_{3}$ induce a current around each $\mathrm{Si}$ atom, and a relatively weak total paratropic ring current (Fig. 7).

The ring current of the protonated $\mathrm{Si}_{3} \mathrm{H}^{+}$is similar to that of $\mathrm{Si}_{3} \mathrm{Li}^{+}$shown in Figure 7. The effect of both the proton and $\mathrm{Li}^{+}$cation is rather weak but clearly yields a paratropic response to the magnetic field.

Figure 8 schematically displays the contributions of the HOMOs and electron excitations responsible for the ring current in $\mathrm{Si}_{3}$. The model based on orbital contributions gives a plausible explanation for the magnetic responses in both situations. In $\mathrm{Si}_{3}$, the main excitation from HOMO $\left(b_{1}\right)$ to LUMO $+1\left(b_{2}\right)$ which is allowed by a rotational transition $R(z)$, thus produces a paramagnetic current density (Fig. 8). This view is in line with the results depicted in Figure 8 that point out the contributions of the HOMOs to the ring currents that yield in fact dominant contributions in accordance with the symmetry selection rules.

Another way of quantifying the effect of $\mathrm{M}^{+}$on the aromatic character is the nuclear independent chemical shift. ${ }^{[52]}$ The NICS(0) values are calculated. Accordingly, $\mathrm{Si}_{3}$ has a $\mathrm{NICS}(0)$ of $-2.7 \mathrm{ppm}$ whereas that of $\mathrm{Si}_{3} \mathrm{Li}^{+}$is $5.4 \mathrm{ppm}$. The $\mathrm{NICS}_{z z}$ values at two different positions are also computed for the singlet states. The $\mathrm{NICS}_{\mathrm{zz}}(0)$ and $\mathrm{NICS}_{\mathrm{zz}}(1)$ for $\mathrm{Si}_{3} \mathrm{H}^{+}$ amount to 10 and 18 ppm, respectively, whereas these values for $\mathrm{Si}_{3} \mathrm{Li}^{+}$are 21 and $20 \mathrm{ppm}$, respectively. In both singlet charged species, an antiaromatic character is quite pronounced in agreement with the ring current. According to the NICS values and the ring current, the singlet $\mathrm{Si}_{3}$ can best be considered as a nonaromatic, if not antiaromatic, compound. Protonation and attachment of an alkali metal cation render the three-membered ring antiaromatic.

\section{Concluding Remarks}

In this theoretical study, we revisited the $\Delta E_{\mathrm{ST}}$ of the silicon trimer $\mathrm{Si}_{3}$ using different quantum chemical wavefunctionbased and DFT methods, and probed the effects of the protonation and attachment of alkali metal cations. From the computed results, the main conclusions emerge as follows:

i. Both the singlet and triplet states of $\mathrm{Si}_{3}$ can be considered as basically degenerate.

ii. An intersystem crossing between both states is possible at a point having an apex bond angle of around $\alpha=68 \pm 2^{\circ}$ which is calculated to be at $16 \pm 3 \mathrm{~kJ} / \mathrm{mol}$ above the ground state.

iii. The proton and alkali metal cations $\mathrm{Li}^{+}, \mathrm{Na}^{+}$, and $\mathrm{K}^{+}$ exert a small effect on the singlet-triplet separation of $\mathrm{Si}_{3} \mathrm{M}^{+}$. While $\mathrm{H}^{+}, \mathrm{Li}^{+}$, and $\mathrm{Na}^{+}$cations tend to prefer the low-spin state, the heavier $\mathrm{K}^{+}$cation slightly favor the triplet state.

iv. The singlet trimer $\mathrm{Si}_{3}$ can be considered as a basically nonaromatic species. Attachment of a proton or a $\mathrm{Li}^{+}$ cation to $\mathrm{Si}_{3}$ renders the singlet three-membered ring anti-aromatic.

\section{Acknowledgments}

TDH thanks the Ministry of Education and Training of Vietnam for a doctoral scholarship (program 911). We are indebted to the $K U$ Leuven Research Council (GOA, IDO, IRO programs) for continuing support. The authors are grateful to Dr. Remco Havenith for allowing us making the ring current maps on his computers at the University of Groningen, The Netherlands.

Keywords: silicon trimer $\cdot$ singlet-triplet gap $\cdot$ proton affinity - metal cation affinities - ring current - electron localization function · $\operatorname{CCSD}(\mathrm{T}) / \mathrm{CBS} \cdot \mathrm{CCSDT} \cdot \mathrm{CCSDTQ} \cdot \mathrm{G} 4$ method

How to cite this article: N. M. Tam, T. D. Hang, H. T. Pham, H. T. Nguyen, M. P. Pham-Ho, P. A. Denis, M. T. Nguyen J. Comput. Chem. 2015, DOI: $10.1002 /$ jcc.23856

Additional Supporting Information may be found in the online version of this article.

[1] E. C. Honea, Nature (London) 1993, 366, 42

[2] K. M. Ho, Nature (London) 1998, 392, 582. 
[3] (a) K. D. Sattler, Handbook of Nanophysics. Clusters and Fullerenes; CRC Press: London, UK, 2011; (b) V. Kumar, Nanosilicon; Elsevier: The Netherlands, 2008.

[4] (a) V. T. Ngan, P. Claes, P. Grüne, E. Janssens, G. Meijer, A. Fielicke, M. T. Nguyen, P. J. Lievens, Am. Chem. Soc. 2010, 132, 15589; (b) A. Fielicke, J. T. Lyon, M. Haertelt, G. Meijer, P. Claes, J. de Haeck, P. Lievens, J. Chem. Phys. 2009, 131, 171105; (c) J. T. Lyon, P. Gruene, A. Fielicke, G. Meijer, E. Janssens, P. Claes, P. Lievens, J. Am. Chem. Soc. 2009, 131, 1115.

[5] T. P. Martin, H. Schaber, Z. Phys. B 1979, 35, 61

[6] J. Cernicharo, C. Kahane, J. Gomez-Gonzalez, M. Guelin, Astron. Astrophys. 1986, 167, L9.

[7] L. A. Bloomfield, R. R. Freeman, W. L. Brown, Phys. Rev. Lett. 1985, 20, 2246.

[8] Y. Liu, S. C. O'Brian, Q. L. Zhang, F. K. Tittle, R. F. Curl, R. E. Smalley, J. Chem. Phys. 1986, 85, 7434 and references therein.

[9] (a) T. N. Kitsopoulos, C. J. Chick, A. Weaver, D. M. Neumark, J. Chem Phys. 1990, 93, 6108.; (b) C. Arnold, D. M. Neumark, J. Chem. Phys. 1993, 100, 1797.

[10] C. B. Winstead, K. X. He, D. Grantier, T. Hammond, J. L. Gole, Chem. Phys. Lett. 1991, 181, 222.

[11] S. Li, R. J. van Zee, W. Weltner, Jr., K. Raghavachari, Chem. Phys. Lett. 1995, 243, 275

[12] M. C. McCarthy, P. Thaddeus, Phys. Rev. Lett. 2003, 90, 213003.

[13] N. J. Reilly, D. L. Kokkin, X. Zhuang, V. Gupta, R. Nagarajan, R. C. Fortenberry, J. P. Maier, T. C. Steimle, J. F. Stanton, M. C. McCarthy, J. Chem. Phys. 2012, 136, 194307.

[14] O. Kostko, S. R. Leone, M. A. Duncan, M. Ahmed, J. Phys. Chem. A 2010, 114, 3176.

[15] J. De Haeck, S. Bhattacharyya, H. T. Le, D. Debruyne, N. M. Tam, V. T. Ngan, E. Janssens, M. T. Nguyen, P. Lievens, Phys. Chem. Chem. Phys. 2013, 14, 8542, and references therein.

[16] G. Pacchioni, J. Koutecky, J. Chem. Phys. 1985, 84, 3301.

[17] R. S. Grev, H. F. Schaefer, Chem. Phys. Lett. 1985, 119, 111.

[18] J. R. Sabin, J. Oddersgede, G. H. F. Diercksen, N. E. Gruene, J. Chem. Phys. 1986, 84, 354.

[19] K. Balasubramanian, Chem. Phys. Lett. 1986, 125, 400.

[20] (a) K. Raghavachari, J. Chem. Phys. 1985, 83, 3525; (b) C. M. Rohlfing, K. Raghavachari, J. Chem. Phys. 1992, 96, 2114; (c) K. Raghavachari, L. A. Curtius, In Quantum Mechanical Electronic Structure Calculations with Chemical Accuracy, S. R. Langhoff, Ed.; Kluwer: The Netherlands, 1995, pp 139-171.

[21] D. A. Dixon, J. L. Gole, Chem. Phys. Lett. 1992, 188, 560.

[22] R. Fournier, S. B. Sinnott, A. DePristo, J. Chem. Phys. 1992, 97, 4149.

[23] G. J. A. Hayward, S. J. M. Hughes, E. I. V. Nagy-Felsobuki, L. P. Alderidge, Mol. Phys .1997, 92, 177.

[24] P. Garcia-Fernandez, J. E. Boggs, J. F. Stanton, J. Chem. Phys. 2007, 126, 074305.

[25] N. M. Tam, V. T. Ngan, J. De Haeck, S. Bhattacharyya, H. T. Le, E. Janssens, P. Lievens, M. T. Nguyen, J. Chem. Phys. 2013, 136, 024301, and references therein.

[26] N. M. Tam, M. T. Nguyen, Chem. Phys. Lett. 2013, 584, 147, and references therein.

[27] (a) P. Rocabois, C. Chatillon, C. Bernard, High Temp. High Press. 1995, 27, 3; (b) P Rocabois, C. Chatillon, C. Bernard, F. Genet, High Temp. High Press. 1995, 27, 25.

[28] R. W. Schmude, Q. Ran, K. A. Gingerich, J. E. Kingcade, J. Chem. Phys. 1995, 102, 2574.

[29] A. Van Orden, R. J. Saykally, Chem. Rev. 1998, 98, 2313.

[30] P. Gruene, A. Fielicke, G. Meijer, E. Janssens, V. T. Ngan, M. T. Nguyen, P. Lievens, Chem. Phys. Chem. 2008, 9, 811

[31] G. Gopakmar, X. Wang, L. Lin, J. De Haeck, P. Lievens, M. T. Nguyen, J. Phys. Chem. C 2009, 113, 10858.

[32] M. J. Frisch, G. W. Trucks, H. B. Schlegel, G. E. Scuseria, M. A. Robb, J. R. Cheeseman, J. A. Montgomery, Jr., T. Vreven, K. N. Kudin, J. C. Burant, J. M. Millam, S. S. lyengar, J. Tomasi, V. Barone, B. Mennucci, M. Cossi, G. Scalmani, N. Rega, G. A. Petersson, H. Nakatsuji, M. Hada, M. Ehara, K. Toyota, R. Fukuda, J. Hasegawa, M. Ishida, T. Nakajima, Y.
Honda, O. Kitao, H. Nakai, M. Klene, X. Li, J. E. Knox, H. P. Hratchian, J. B. Cross, V. Bakken, C. Adamo, J. Jaramillo, R. Gomperts, R. E. Stratmann, O. Yazyev, A. J. Austin, R. Cammi, C. Pomelli, J. Ochterski, P. Y. Ayala, K. Morokuma, G. A. Voth, P. Salvador, J. J. Dannenberg, V. G. Zakrzewski, S. Dapprich, A. D. Daniels, M. C. Strain, O. Farkas, D. K. Malick, A. D. Rabuck, K. Raghavachari, J. B. Foresman, J. V. Ortiz, Q. Cui, A. G. Baboul, S. Clifford, J. Cioslowski, B. B. Stefanov, G. Liu, A. Liashenko, P. Piskorz, I. Komaromi, R. L. Martin, D. J. Fox, T. Keith, M. A. Al-Laham, C. Y. Peng, A. Nanayakkara, M. Challacombe, P. M. W. Gill, B. G. Johnson, W. Chen, M. W. Wong, C. Gonzalez, J. A. Pople, Gaussian 09 Revision B.01, Gaussian, Wallingford, CT, 2009

[33] H.-J. Werner, P. J. Knowles, R. Lindh, F. R. Manby, M. Schütz, P. Celani, T. Korona, A. Mitrushenkov, G. Rauhut, T. B. Adler, R. D. Amos, A. Bernhardsson, A. Berning, D. L. Cooper, M. J. O. Deegan, A. J. Dobbyn, F. Eckert, E. Goll, C. Hampel, G. Hetzer, T. Hrenar, G. Knizia, C. Köppl, Y. Liu, A. W. Lloyd, R. A. Mata, A. J. May, S. J. McNicholas, W. Meyer, M. E. Mura, A. Nicklass, P. Palmieri, K. Pflüger, R. Pitzer, M. Reiher, U. Schumann, H. Stoll, A. J. Stone, R. Tarroni, T. Thorsteinsson, M. Wang, A. Wolf, MOLPRO, Version 2008, A package of ab initio programs, 2006.

[34] CFOUR, Coupled-Cluster techniques for Computational Chemistry, a quantum-chemical program package by J. F. Stanton, J. Gauss, M. E. Harding, P. G. Szalay with contributions from A. A. Auer, R. J. Bartlett, U. Benedikt, C. Berger, D. E. Bernholdt, Y. J. Bomble, L. Cheng, O. Christiansen, M. Heckert, O. Heun, C. Huber, T.-C. Jagau, D. Jonsson, J. Jusélius, K. Klein, W. J. Lauderdale, D. A. Matthews, T. Metzroth, L. A. Mück, D. P. O'Neill, D. R. Price, E. Prochnow, C. Puzzarini, K. Ruud, F. Schiffmann, W. Schwalbach, C. Simmons, S. Stopkowicz, A. Tajti, J. Vázquez, F. Wang, J. D. Watts and the integral packages MOLECULE (J. Almlöf and P. R. Taylor), PROPS (P. R. Taylor), ABACUS (T. Helgaker, H. J. Aa. Jensen, P. Jørgensen, J. Olsen), and ECP routines by A. V. Mitin and C. van Wüllen, 2010. Available at: http://www.cfour.de.

[35] M. Kállay, Z. Rolik, I. Ladjánszki, L. Szegedy, B. Ladóczki, J. Csontos, B. Kornis, MRCC, A Quantum Chemical Program Suite. See also Z. Rolik, L. Szegedy, I. Ladjánszki, B. Ladóczki, and M. Kállay, J. Chem. Phys. 2013, 139, 094105, Available at: www.mrcc.hu.

[36] M. Kállay, J. Gauss, J. Chem. Phys. 2005, 123, 214105.

[37] L. A. Curtiss P.C. Redfern, K. Raghavachari, J. Chem. Phys. 2007, 126, 084108.

[38] R. A. Kendell, T. H. Dunning, R. J. Harrison, J. Chem. Phys. 1992, 96, 6796.

[39] K. A. Peterson, D. E. Woon, T. H. Dunning, J. Chem. Phys. 1994, 100, 7410.

[40] B. Silvi, A. Savin, Nature 1994, 371, 683.

[41] E. Steiner, P. W. Fowler, J. Phys. Chem. A 2001, 105, 9553.

[42] M. F. Guest, I. J. Bush, H. J. J. van Dam, P. Sherwood, J. M. H. Thomas, J. H. van Lenthe, R. W. A. Havenith, J. Kendrick, Mol. Phys. 2005, 103 719.

[43] P. Lazzeretti, M. Malagoli, R. Zanasi, Chem. Phys. Lett. 1994, 220, 299.

[44] A. D. Walsh, J. Chem. Soc. 1953, 2260.

[45] K. Anderson, P. A. Malmqvist, B. O. Roos, J. Chem. Phys. 1992, 96, 1218.

[46] T. V. Tan, M. F. A.Hendrickx, J. Chem. Theory. Comput. 2011, 7, 210.

[47] A. K. Wilson, T. H. Dunning, J. Chem. Phys. 2003, 119, 11712.

[48] NIST Chemistry Web Book. Available at: http://webbook.nist.gov/chemistry/.

[49] G. Gopakumar, P. Lievens, M. T. Nguyen, J. Phys. Chem. A 2007, 111, 4353.

[50] G. Gopakumar, P. Lievens, M. T.Nguyen, J. Chem. Phys. 2006, 124, 214312.

[51] R. W. A. Havenith, P. W. Fowler, Phys. Chem. Chem. Phys. 2006, 8, 3383.

[52] P. V. R. Schleyer, C. Maerker, A. H. Dransfeld, Jiao, N. J. R. v. E. Hommes, J. Am. Chem. Soc. 1996, 118, 6317.

Received: 13 August 2014

Revised: 30 November 2014

Accepted: 15 December 2014

Published online on 00 Month 2015 